\title{
Redesign of Bus Services Using Quality Function Deployment (QFD) to Improve Services to Passenger (Case Study: PO XYZ)
}

\section{Perancangan Ulang Pelayanan Bus Menggunakan Pendekatan Quality Function Deployment (QFD) Untuk Meningkatkan Pelayanan Penumpang (Case Study PO XYZ)}

\author{
Denny Nurkertamanda ${ }^{1}$, Fakhril Husain ${ }^{1}$, Yusuf Widharto ${ }^{1}$ \\ ${ }^{1}$ Departemen Teknik Industri \\ Fakultas Teknik Universitas Diponegoro \\ email:nurkerta@gmail.com \\ doi: https://doi.org/10.31315/opsi.v14i1.4747
}

Received: $10^{\text {th }}$ May 2021; Revised: $3^{\text {rd }}$ June 2021; Accepted: $21^{\text {st }}$ June 2021;

Available online: 24 ${ }^{\text {th }}$ June 2021; Published regularly: June 2021

\begin{abstract}
For products in the form of services, customer satisfaction is the most important thing because consumers see services from what other consumers say. As with the PO XYZ also use service which relies on passenger satisfaction. PO XYZ have an experience in reduced consumer satisfaction and with the competitor rise the passenger turn to another competitor. Because of this, it is necessary to conduct this research, for winning customer PO XYZ heart by listening passenger desires. This research used Quality Function Deployment (QFD) which only reached the second phase. Data collection through open passenger questionnaires. In the first phase, product planning, it was found that cleanliness of the bus was a major factor that had to be addressed by PO XYZ of $9.477 \%$. The first phase output in the form of technical characteristics becomes the second phase input, namely design planning. In the second phase four suitable service design alternatives were made. Of the four design alternatives, a third service design is obtained which is the choice with a value of 4.74 from scale 6. This shows that the third alternative service should be implemented as an effort to improve quality in meeting passenger satisfaction of $P O X Y Z$.
\end{abstract}

Keywords: Costumer; QFD; Service

\begin{abstract}
ABSTRAK
Pada produk yang menjual jasa, kepuasan konsumen menjadi sebuah hal yang paling penting karena konsumen melihat layanan dari apa yang pelanggan lain rasakan dan utarakan. Seperti halnya pada layanan PO XYZ yang mengandalkan kepuasan penumpang. PO XYZ pernah mengalami penurunan kepuasaan konsumen disamping itu juga kemunculan pesaing membuat konsumen beralih. Karena hal tersebut yang menjadikan latar belakang munculnya penelitian ini yaitu pembuatan layanan PO XYZ yang lebih baik dengan mengutamakan keinginan penumpang. Penelitian menggunakan Quality Function Deployment (QFD) sampai fase kedua. Pengumpulan data melalu kuisioner penumpang secara terbuka. Pada fase pertama yaitu perencanaan produk menghasilkan bahwa kebersihan bus menjadi faktor utama yang harus dibenahi oleh PO XYZ sebesar 9,477\%. Output fase pertama yang berupa karakteristik teknis menjadi input fase kedua yaitu perencanaan desain. Pada fase kedua dibuat empat alternatif desain layanan yang sesuai. Dari keempat alternatif desain, didapatkan desain layanan ketiga yang menjadi pilihan dengan nilai 4,74 dari skla 6. Hal ini menjunjukan bahwa layanan alternatifketiga sebaiknya diterapkan sebagai upaya peningkatan kualitas dalam memenuhi kepuasan penumpang PO XYZ.
\end{abstract}

Kata Kunci: Konsumen; QFD; Pelayanan 


\section{PENDAHULUAN}

Moda transportasi bus sendiri menjadi moda transportasi yang telah ada sejak tahun 1930an. Moda transportasi bus menjadi primadona pada kisaran tahun 90an di mana masyarakat Indonesia banyak menggunakan bus untuk berpergian baik dari satu kota ke kota lain maupun ke luar provinsi. Penumpang bus sempat beralih ke moda transportasi kereta api dan pesawat terbang. Hal ini dikarenakan bus yang sudah perlu diremajakan serta belum memenuhinya perkembangan jalan di Indonesia yang menyebabkan bus kadang dirasa kurang tepat waktu dan sering terlambat. Moda transportasi pesawat dan kereta yang selalu tepat waktu, nyaman dan masih terjangkau menjadi pilihan para penumpang.

Kepuasaan penumpang mempengaruhi keinginan penumpang untuk berpindah ke penyedia jasa yang lainnya (Wijaya dan Herdioko, 2010). Beberapa penelitian mencoba menggunakan layanan Bus Rapid Transit (BRT) untuk mencoba menarik pengguna dari angkutan pribadi ke angkutan umum dan mereka memang menemukan adanya potensi kemungkinan pergeseran moda angkutan dengan layanan yang diberikan BRT (Satiennam. T, dkk, 2016)( Wang L, dkk, 2013)(Steg L, 2003)

Kepuasan pelanggan didefinisikan sebagai suatu keadaan di mana kebutuhan, keinginan, dan harapan pelanggan dapat terpenuhi oleh produk yang dikonsumsi (Majid, 2011). Hal ini akan membuat fluktuasi jumlah penumpang bagi suatu perusahaan mudah untuk berubah. Kualitas pelayanan yang baik berpengaruh terhadap kepuasaan pelanggan atau penumpang (Ikasari dkk., 2013). Kepuasan pelanggan akan menjaga suatu loyalitas pelanggan terhadap perusahaan (Firmansyah, D dan Prihandono, 2018). Loyalitas memiliki dua aspek : yang pertama adalah perilaku berkelanjutan setiap orang untuk membeli produk dan yang kedua berkaitan dengan sikap dan emosi pelanggan (Zhao, J., 2014)

Pembuatan layanan yang lebih baik menjadi hal yang diperlukan untuk meningkatan pelayanan yang ada. Penggunaan metode Quality Function Deployment (QFD) menjadi salah satu pilihan yang baik dalam merangkum suara konsumen. QFD didefinisikan sebagi suatu sistem yang menerjemahkan kebutuhan pengguna ke dalam spesifikasi perusahaan dalam setiap langkah proses produksi yaitu pemasaran, pengembangan, produksi, penjualan, dan layanan (Andersson, 1991).

Dengan menggunakan pendekatan QFD kebutuhan pelanggan dan desain diprioritaskan dengan menggunakan Teknik konsensus grup yang menyediakan alat pengambilan keputusan untuk penentuan solusi sesuai dengan permintaan pelanggan yang sebenarnya (Natee, Low, \& Teo, 2016)

Pada dasarnya pembuatan layanan jasa dan produk akan sedikit berbeda. Scherkenbach (1991) mengemukakan istilah kualitas sebagai suatu hal yang ditentukan oleh pelanggan, pelanggan menginginkan produk dan jasa yang sesuai dengan kebutuhan dan harapannya pada suatu tingkat harga tertentu yang menunjukan nilai produk tersebut. Kotler (1997) menyebutkan bahwa kualitas jasa merupakan suatu kondisi yang dinamis berhubungan dengan jasa dalam pemenuhan atau melebihi harapan seorang konsumen. Pada sektor angkutan umum, sangat penting untuk memenuhi permintaan pelanggan atau penumpang dalam hal kriteria kualitas tertentu seperti frekuensi, kenyamanan, keamanan sehingga, diperlukan metodologi untuk menerjemahkan permintaan penumpang ini ke dalam kriteria kualitas (Deveci M., dkk, 2019). Penelitian ini bertujuan untuk mengetahui kriteria kualitas yang diinginkan oleh konsumen sehingga dapat menjadi bahan masukan dalam penyusunan desain layanan kepada konsumen.

Penelitian QFD telah dilaksanakan pada sektor layanan transportasi dengan hasil yang memuaskan (Deveci, Canitez, \& Demirel, 2016; Liden \& Edvardsson, 2003)

\section{METODE}

Pada penelitian yang dilakukan menggunakan metode penelitian Quality Function Deployment dimana melalui fase 1 dan fase dua. Metode penelitian yang dilakukan dapat dilihat pada Gambar 1 .

\subsection{Deskripsi Produk}

Sebelum melakukan perancangan layanan PO XYZ, layanan yang akan dibuat dideskripsikan terlebih dahulu. Deskripsi meliputi fungsi layanan, komponen yang 
terlibat dalam layanan, proses yang terjadi dalam layanan, input dan output layanan yang diberikan.

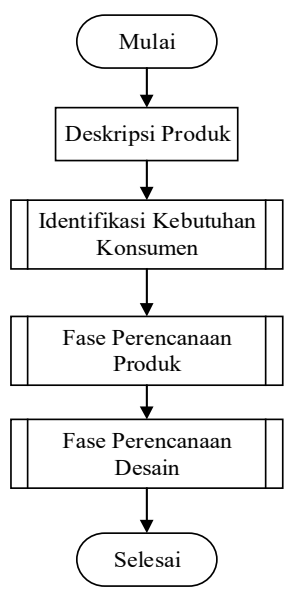

Gambar 1. Metode Penelitian

\subsection{Fase Perencanaan Produk}

Pada fase perencanaan produk berisi tentang pengumpulan data mentah yaitu voice of customer (voc) yang dirubah menjadi kebutuhan konsumen. Kebutuhan konsumen dijawab dengan menggunakan karakteristik teknis yang bisa terdiri dari satu atau dua karakteristik teknis dan diberi dengan satuan. Keduanya dibuat sebuah matriks hubungan yang digunakan untuk menentukan kepentingan karakteristik teknis. Selain pencarian kebutuhan dilakukan juga sebuah benchmarking yaitu pembandingan dengan perusahaan lain yang digunakan sebagai pesain. Positioning dilakukan untuk menempatkan dimana PO XYZ menempatkan pada persaingan yang ada. Hasil akhir dari fase pertama adalah House of Quality (HOQ). Selain $\mathrm{HOQ}$, fase pertama juga membuat sebuah black box dan white box. Keduanya merupakan alur dari proses yang ada dalam perusahaan $\mathrm{PO}$ XYZ dari input sampai output.

\subsection{Fase Perencanaan Desain}

Fase perancangan desain merupakan tahapan kedua dari metode QFD. Input pada fase ini adalah output pada fase sebelumnya yaitu analisis fungsi produk dan spesifikasi produk. Fase perancangan desain merupakan penerjemahan kebutuhan teknis menjadi subsistem-subsistem kritis atau karakteristikkarakteristik part. Tujuan fase ini adalah mengetahui informasi yang menjelaskan tentang komponen-komponen spesifik agar dapat menjawab keinginan konsumen terhadap layanan dari PO XYZ. Pada fase ini mencari karakteristik part yang memiliki nilai kepentingan tertinggi. Hasil akhir dari fase ini merupakan sebuah desain layanan yang terpilih oleh perusahaan dan nantinya bakal diterapkan.

Selain ketiga langkah diatas, penelitian juga melakukan analisis hasil dan menarik kesimpulan sebagai bagian akhir dari sebuah

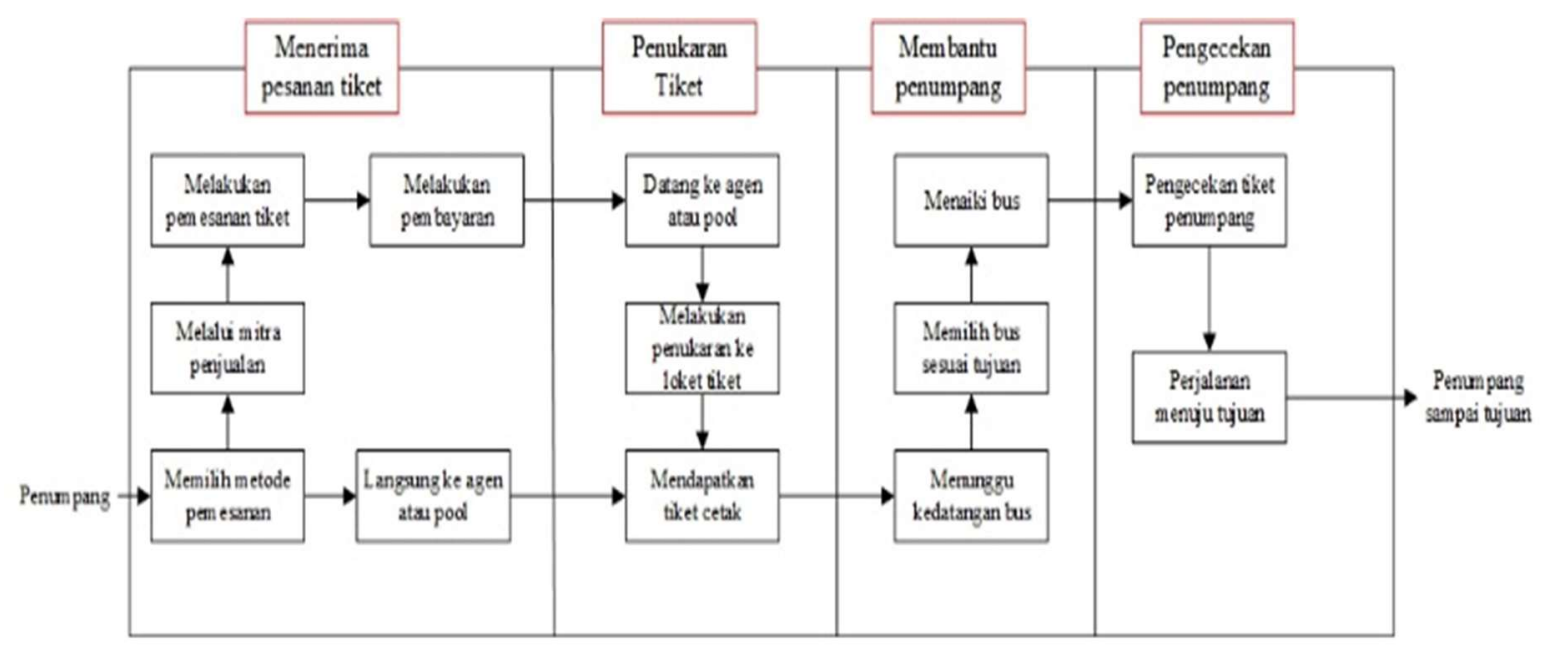

Gambar 2. White Box XYZ 
penelitian. Kesimpulan berisi jawaban dari tujuan yang ingin dicapai oleh seorang peneliti.

\section{HASIL DAN PEMBAHASAN}

\subsection{Deskripsi Layanan}

Produk yang dikembangkan pada penelitian ini adalah produk jasa yang berupa layanan yaitu layanan pada PO XYZ. PO XYZ merupakan perusahaan penyedia jasa transportasi darat khususnya bus. Jasa layanan ini akan mengantarkan seseorang dari satu tempat ke tempat lain. Secara garis besar pelayanan yang akan dilalui oleh penumpang dimulai dari penumpang memesan tiket baik secara online (mitra penjualan) maupun offline (agen dan loket penjualan). Pembelian tiket online harus ditukarkan terlebih dahulu pada agen atau loket yang ada untuk melakukan cetak tiket. Penumpang akan menunggu kedatangan bus di pool atau di agen dan melakukan perjalanan menggunakan bus sampai tempat tujuan.

\subsection{Proses Layanan}

Untuk menjelaskan rangkaian proses layanan yang berada pada PO XYZ maka dibuat sebuah white box. White box menjelaskan proses yang lebih jelas pada pelayanan PO XYZ. White box merupakan penjabaran dari sebuah black box yang lebih sempit. Penjelasan mengenai white box PO XYZ dapat dilihat pada Gambar 2

\subsection{Kebutuhan Konsumen}

Hasil dari pengumpulan data suara konsumen dan melakukan perubahan kepada kebutuhan konsumen, didapatkan tiga belas kebutuhan konsumen yang menjadi prioritas untuk dipenuhi dalam perbaikan layanan yang ada. Ketiga belas kebutuhan konsumen juga dilakukan penilain kepentingan dengan mendapatkan hasil yang dapat dilihat pada Tabel 1.

Kebutuhan perjalanan nyaman, aman dan tenang menjadi peringkat pertama dengan bobot 7.36 dari skala 10. Hal ini menjadi perhatian bahwa kebutuhan konsumen tersebut harus menjadi prioritas dalam perubahan layanan. Penumpang akan mencari pelayanan dari sebuah perusahaan perjalanan yang memberikan perjalanan yang nyaman, aman dan tenang. Kebutuhan dengan bobot terkecil pegawai berpenampilan khusus dengan bobot
Tabel 1. Kebutuhan Konsumen dan Nilai Kepentingannya

\begin{tabular}{|c|c|c|}
\hline Kebutuhan Konsumen & Bobot & Peringkat \\
\hline Perjalanan nyaman, aman dan tenang & 7.36 & 1 \\
\hline Bus datang tepat waktu & 6.78 & 3 \\
\hline $\begin{array}{l}\text { Barang bawaan ditempatkan dengan } \\
\text { rapi }\end{array}$ & 4.91 & 9 \\
\hline Fasilitas makan dan minum & 4.14 & 12 \\
\hline Pembelian dan penukaran tiket mudah & 7.04 & 2 \\
\hline Prosedur pelayanan mudah dipahami & 5.04 & 7 \\
\hline Fasilitas umum bersih & 6.00 & 5 \\
\hline Area tunggu yang nyaman dan aman & 4.62 & 10 \\
\hline $\begin{array}{l}\text { Pelayanan PO XYZ memiliki standar } \\
\text { sama }\end{array}$ & 4.26 & 11 \\
\hline Pegawai berpenampilan khusus & 3.50 & 13 \\
\hline $\begin{array}{l}\text { Pegawai melayani dengan ramah saat } \\
\text { bekerja }\end{array}$ & 6.45 & 4 \\
\hline $\begin{array}{l}\text { Pemberian informasi tentang } \\
\text { perjalanan bus }\end{array}$ & 5.39 & 6 \\
\hline Fasilitas charger hp saat menunggu bus & 4.95 & 8 \\
\hline
\end{tabular}

Tabel 2. Karakteristik Teknis

\begin{tabular}{cll}
\hline No & Karakteristik Teknis & Satuan \\
\hline 1 & Suhu udara & C \\
2 & Kebersihan bus & Subj \\
3 & Bentuk kursi & List \\
4 & Jarak antar kursi & Cm \\
5 & Perawatan mesin & Jumlah \\
6 & Keberangkatan bus & Waktu \\
7 & Identitas barang & List \\
8 & Dimensi bagasi & Cm \\
9 & SOP layanan & List \\
10 & Harga tiket & Rp \\
11 & Sosialisasi & Jumlah \\
12 & Jumlah Antrian & Jumlah \\
13 & Perawatan fasilitas & Jumlah \\
14 & Kebersihan lingkungan & Subj \\
15 & Peraturan penggunaan fasilitas & List \\
16 & Jumlah kursi & Jumlah \\
17 & Training pegawai & Jumlah \\
18 & Identitas diri & List \\
19 & Pengawasan pegawai & Jumlah \\
20 & Penggunaan media social & List \\
21 & Bentuk kursi tunggu & List \\
22 & Desain area tunggu & List \\
23 & Stopkontak & Jumlah \\
\hline
\end{tabular}

3.50 skala 10. Pegawai berpenampilan khusus memberikan dampak yang kecil bagi penumpang dalam pemenuhan kepuasan penumpang. 


\subsection{Karakteristik Teknis}

Pemenuhan kebutuhan konsumen dilakukan dengan karakteristik teknis (Tabel 2) sesuai dengan kebutuhan yang diinginkan, karakteristik teknis yang ada juga diberi suatu satuan. Daftar karakteristik teknis dan satuan yang digunakan akan menjadi sebuah matriks terukur. Satuan yang digunakan merupakan suatu satuan konvensional seperti centimeter dan celcius. Selain penggunaan satuan konvensional juga terdapat pengukuran subjektif dan satuan daftar (list).

Dari hasil perhitungan matrik yang dilakukan dengan kebutuhan konsumen didapatkan bahwa kebersihan bus mendapat nilai paling besar yaitu $9,477 \%$. Peringkat kedua didapatkan oleh pengawasan pegawai dengan nilai $8,134 \%$. Sedangkan peringkat terakhir didapatkan oleh karakteristik teknis dimensi bagasi dengan skor $0,373 \%$.

\subsection{Benchmarking}

Benchmarking pada penelitian ini dilakukan dengan perusahaan PO DEF dan PO PQR sebagai kompetitor. Benchmarking dilakukan terhadap ketiga belas kebutuhan konsumen yang ada dengan menggunakan penilaian oleh penumpang yang menaiki kedua perusahaan jasa layanan tersebut. Hasil benchmarking dan positioning PO XYZ dapat dilihat pada Tabel 3

Tabel 3. Hasil Benchmarking PO XYZ dan kompetitor

\begin{tabular}{|c|c|c|c|}
\hline No & Kebutuhan Konsumen & $\begin{array}{c}\text { PO } \\
\text { DEF }\end{array}$ & $\begin{array}{c}\text { PO } \\
\text { PQR }\end{array}$ \\
\hline 1 & Perjalanan nyaman, aman dan tenang & 4 & 3 \\
\hline 2 & Bus datang tepat waktu & 3 & 3 \\
\hline 3 & Barang bawaan ditempatkan dengan rapi & 3 & 4 \\
\hline 4 & Fasilitas makan dan minum & 3 & 4 \\
\hline 5 & Pembelian dan penukaran tiket mudah & 4 & 4 \\
\hline 6 & Prosedur pelayanan mudah dipahami & 3 & 3 \\
\hline 7 & Fasilitas umum bersih & 3 & 4 \\
\hline 8 & Area tunggu yang nyaman dan aman & 4 & 3 \\
\hline 9 & Pelayanan PO XYZ memiliki standar sama & 3 & 3 \\
\hline 10 & Pegawai berpenampilan khusus & 4 & 4 \\
\hline 11 & Pegawai melayani dengan ramah saat bekerja & 4 & 3 \\
\hline 12 & Pemberian informasi tentang perjalanan bus & 4 & 4 \\
\hline 13 & Fasilitas charger hp saat menunggu bus & 4 & 3 \\
\hline
\end{tabular}

Benchmarking yang dilakukan oleh PO XYZ menempatkan pada nilai 4 di hampir semua kebutuhan konsumen. Hal ini dikarenakan PO XYZ akan berusaha memaksimalkan kemampuan dalam memenuhi kebutuhan penumpang dan mencapai kepuasan penumpang dengan tinggi untuk mendapatkan loyalitas bagi perusahaan.

\subsection{House of Quality}

House of Quality (Gambar 3)merupakan gabungan dari semua bagian baik karakteristik teknis, kebutuhan konsumen, benchmarking dan lain lain. Sebagai output pada fase pertama Quality Function Deployment.

\subsection{Komponen Layanan}

Pada fase kedua, langkah pertama adalah menentukan karakteristik part yaitu dengan melakukan identifikasi dari komponen (part) penyusun pelayanan PO XYZ. Identifikasi bagian penyusun pelayanan PO XYZ dilakukan berdasarkan diagram fungsi pohon (function tree diagram). Pada pelayanan $\mathrm{PO} \mathrm{XYZ}$ diuraikan menjadi beberapa subsistem. Subsistem yang ada diuraikan menjadi komponen (part) pelayanan.

Komponen layanan yang ada berjumlah Sembilan yaitu ada pegawai, alat cetak, tiket, biaya, penumpang, media sosial, mitra penjualan, alat perawatan, jadwal dan peraturan. Komponen part ini akan digunakan dalam pembuatan karakteristik part sebagai bagian dari fase kedua. Karakteristik part merupakan jawaban dari karakteristik teknis secara lebih terperinci.

\subsection{Karakteristik Part}

Hasil dari pencarian karakteristik part sesuai dengan 25 karakteristik teknis yang ada, didapatkan 55 karakteristik part yang harus dipenuhi. Salah satu karakteristik part yang ada adalah peraturan manajemen yang merupakan karakteristik dari part peraturan. Setelah dilakukan perhitungan menggunakan hubungan dengan karakteristik teknis didapatkan nilai bagi setiap karakteristik part. Peringkat didapatkan dengan melihat nilai dengan 


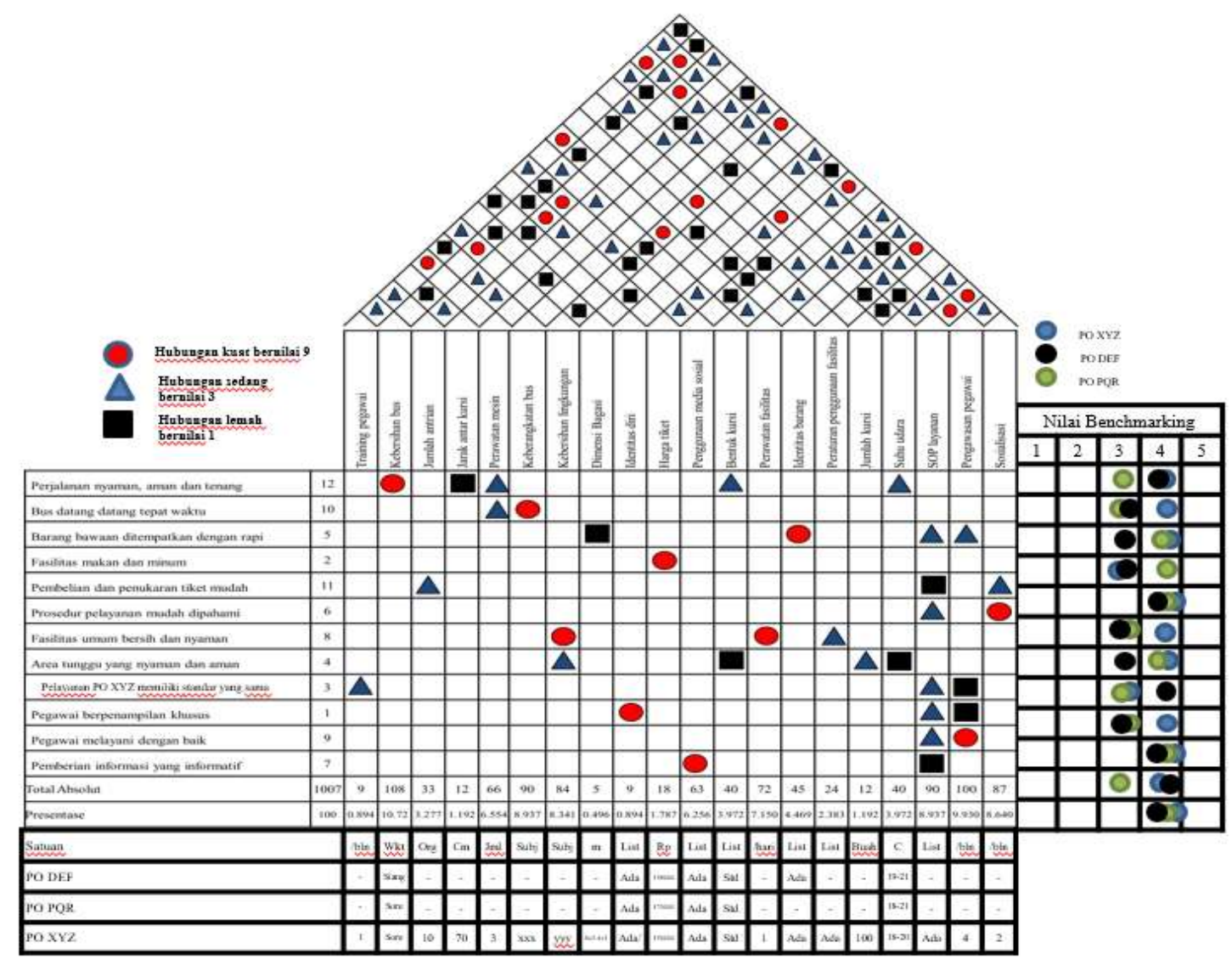

Gambar 3. House of Quality Layanan PO XYZ

presentase terbesar. Karakteristik part yang memiliki nilai terbesar adalah peraturan manajemen yang memiliki nilai 10,260\% dimana hal ini menjadi perhatian bagi perusahaan bahwa ketika membuat suatu peraturan manajemen harus memperhitungkan pelayanan terhadap penumpang yang ada. Selain peraturan manajemen, nilai yang memiliki kepentingan lumayan besar adalah jenis penumpang dengan nilai 7,398. Jenis penumpang akan mempengaruhi layanan seperti apa yang bakal diberikan kepada penumpang tersebut. Karakteristik part dengan nilai terendah banyak diperoleh oleh beberapa karakteristik part dengan nilai yang sama yaitu $0,238 \%$. Salah satu yang memiliki nilai terkecil adalah jumlah keberangkatan.

\subsection{Desain Layanan}

Desain layanan dibuat menjadi empat alternative dengan menggunakan sub-subfungsi layanan yang telah diidentifikasi pada tahap analisis fungsional layanan. Dari keempat alternatif layanan yang ada menghasilkan bahwa layanan alternatif ketiga menjadi pilihan dengan skor penilaian 4.74 dari skala nilai 6 . Pelayanan yang ada adalah sebagai berikut:

1. Penjualan tiket secara online dan offline

2. Harus tetap melakukan pencetakan tiket

3. Pembelian melalui website, agen dan loket yang ada

4. Tiket ditukarkan melalui agen dan loket penjualan

5. Kursi tunggu menggunakan kursi stainless

6. Jadwal bus dapat dilihat pada media sosial, agen dan loket

7. Pegawai menggunakan kartu identitas dan seragam

8. Pembersihan mushola setiap hari dan mushola dilarang untuk tempat tidur

9. Mesin dirawat setiap sampai tujuan

10. Kursi menggunakan bahan kulit sintetis, handrest dan bisa diatur

11. Suhu udara pada kelas AC disesuaikan dengan keadaan saat itu

12. Disediakan service makan yang tergabung dengan biaya tiket 
13. Barang bagasi diberi identitas seperti nomor barang

14. Pegawai mencatat tujuan penumpang dan mengingatkan penumpang saat sampai tujuan

15. Memberi toleransi keterlambatan bagi penumpang

\subsection{Pelaksanaan Pelayanan}

Pelaksanaan pelayanan yang dilakukan nantinya harus memperhatikan prioritas baik dalam karakteristik teknis maupun dalam karakteristik part yang telah didapatkan. Hal ini digunakan karena dalam pelaksanaan yang mempertimbangkan prioritas Akan memudahkan PO XYZ dalam mempercepat kepuasaan konsumen dan lebih kuat dalam mempertahankannya

\section{KESIMPULAN}

Pada pembuatan layanan yang menggunakan metode Quality Function Deployment sampai tahap kedua mendapatkan hasil yaitu alternatif solusi ketiga dipilih menjadi layanan yang akan diterapkan. Kebutuhan yang dinyatakan dengan kepentingan tinggi harus menjadi perhatian khusus bagi perusahaan agar tidak kehilangan loyalitas dari para konsumen atau penumpang yang ada.

\section{Saran}

Penelitian yang dilakukan masih memiliki banyak kekurangan dimana pengambilan data masih terbatas dengan online dan perlunya pendekatan secara personal yang lebih banyak kepada penumpang agar mendapatkan hasil yang lebih baik dan menjadi layanan yang benar benar sesuai dengan keinginan pelanggan.

\section{DAFTAR PUSTAKA}

Andersson, R. (1991). QFD: ett system för effektivare produktframtagning. Studentlitteratur.

Deveci, M., Canitez, F., \& Demirel, Ç. (2016). Developing a QFD methodology to increase customer satisfaction in public transport companies. ICENS international conference on engineering and natural science, 24-28 may 2016, Sarajevo, Bosnia and Herzegovina
Muhammet Deveci, Sultan Ceren Öner, Fatih Canitez, Mahir Öner, (2019), Evaluation of service quality in public bus transportation using interval-valued intuitionistic fuzzy QFD methodology, Research in Transportation Business \& Management Volume 33, December 2019 ,

100387.https://doi.org/10.1016/j.rtbm.2 019.100387

Firmansyah, D., dan Prihandono, D. (2018). Pengaruh Kualitas Pelayanan dan Perceived Value terhadap Loyalitas Pelanggan dengan Kepuasan Management Analysis Journal, 7(1), 120-128.

Ikasari, A. U., Suryoko, S., dan Nurseto, S. (2013). Pengaruh Nilai Pelanggan dan Kualitas Pelayanan terhadap Kepuasan Pelanggan (Studi Kasus pada Penumpang KA Kaligung Mas di Stasiun Poncol Semarang). Jurnal Ilmu Administrasi Bisnis, 52-59.

Kotler, P. (1997). Manajemen Pemasaran. Jakarta: Erlangga.

Majid, S. A. (2011). Customer Service Dalam Bisnis Jasa Transportasi. Jakarta: Rajagrafindo Persada.

Natee, S., Low, S. P., \& Teo, E. A. (2016). Decision making and quality function deployment (QFD). Quality function deployment for buildable and sustainable construction (pp. 17-55). Springer Singapore.

Satiennam, T., S. Jaensirisak, W. Satiennam, S. Detdamrong, Potential for modal shift by passenger car and motorcycle users towards Bus Rapid Transit (BRT) in an Asian developing city, IATSS Res. 39 (2016) 121-129.

Scherkenbach, WW.(1991). Deming "s Road to Continual Improvement, Knoxville, USA: SPC Press.

Steg. L, Can public transport compete with the private car? IATSS Res. 27 (2003) $27-35$.

Wang. L., L. Li, B. Wu, Y. Bai, Private car switched to public transit by commuters, in Shanghai, China, Procedia-Social and Behavioral Sciences 96 (2013) 12931303.

Wijaya, P. S. M., dan Herdioko, J. (2010). Pengaruh Kualitas, Persepsi Nilai, Citra, 
Dan Kepuasan Terhadap Loyalitas atau Keinginan Berpindah Penumpang Bus Transjogja. Jurnal Riset Manajemen dan Bisnis, 5(2), 121-151.
Zhao J., V. Webb, P. Shah, Customer loyalty differences between captive and choice transit riders, Transp. Res. Rec. 2415 (2014) 80-88. 